\title{
Analytical Study of a Heat Recovery/Desiccant Cooling System under Tunisian Climatic Conditions
}

\author{
S. Sabek, K. Ben Nasr, R. Chouikh, and A. Guizani
}

\begin{abstract}
The solar potential energy in Tunisia can be used like a principal factor for the operation of new technologies of air conditioning. Studies could be carried out like approaches of simulation, analyzes experimental or both unit. In this paper, we present an analytical solution of heat and mass transfer processes in regenerator and air conditioning system (ACS) cores of a heat recovery /desiccant cooling system (HRDCS) under Tunisia weather conditions. Simulations programs were carried out to test the principal components of the HRDC system. The results show that the coefficient of performance of system improves when we use the renewable energy for heating and cooling. This study is significant and effective to prove the efficiency of such HRDC systems in this country.
\end{abstract}

Index Terms-Air conditioning, liquid desiccant cooling system, simulations, Tunisian climatic conditions.

\section{INTRODUCTION}

Energy consumption in buildings has been increased in recent years with the development of the economy worldwide, recent studies have shown that buildings are responsible for the consumption of about $40 \%$ of the primary energy and the emission of nearly $33 \%$ of the greenhouse gases in the world [1]. Therefore, liquid desiccant cooling technologies has been researched and demonstrated in recent years, focusing on applications such as cooling of human houses, commercial buildings, hospitals. It can be an efficient way to provide cooling and to reduce building energy consumption.

Approximately 30 years ago, [2] accounted for the operation of a device of air-conditioning on a large scale using water- $\mathrm{LiCl}$, where they presented the direct regeneration in collectors open and storage to the cold in the form of regenerated solution. Some investigators tested the use of the organic absorbents, such as tri ethylene glycol (TEG) to reduce the problem of corrosion involved in inorganic salts [3]. Researches [4], [5] have been carried on the liquid desiccant systems for cooling and dehumidification by using solar energy to regenerate the liquid desiccant during the regeneration process and to re-use it for the dehumidification of air. In several cases, the direct regeneration of the liquid desiccant to the sun was considered by using a special type of collector.

Manuscript received April 10, 2014; revised June 27, 2014.

Seifennasr Sabek and Amenallah Guizani are with the Centre des Recherches et des Technologies de l'Energie (CRTEn) PB 95, Hammam Lif 2050, Tunisia (e-mail: Seifennasr.SABEK@gmail.com, amenallah.guizani@crten.rnrt.tn).

Kaouther Ben Nasr is with the Ecole Nationale d'Architecture et d'Urbanisme, Rue El Quods, Carthago 2026, Tunisia (e-mail: kaouther.lazaar@laposte.net).

Ridha Chouikh is with the Institut Supérieur de Mathématiques Appliquées et d'Informatique (ISMAI), Kairouan 3100, Tunisia (e-mail: Ridha.chouikh@yahoo.fr).
Among people who make research and experiments of this type of system are, Mavroudaki [6] presented a review of desiccant dehumidification/cooling systems applications in north Europe and they concluded that there was a potential to use these technologies in the European countries.

Saman and Alizadeh [7] examined a solar system with liquid desiccant air conditioning (LDAC) in the tropical climate of Queensland, Australia (2002). The performance of a LDAC solar system for dehumidification/cooling was studied experimentally and theoretically. It noted that the system is an effective manner to dehumidify and to cool air in hot and wet climates and that the performance of LDAC could be increased by using the optimum flows of air and solution of $1000 \mathrm{~L} / \mathrm{s}$ and $3 \mathrm{~L} / \mathrm{min}$, respectively. In 2006, Gommed and Grossman [8] regarded that the town of Haifa as an ideal place to examine a cooling system placed on the Mediterranean coast with the latitude 33 of north, it has the typical climate of the Mediterranean cities. They concluded that this system has a simple construction, simple capacity storage and an ordering of dirtiness and capacities by using an air-to-air heat exchanger to recovery the thermal heat.

In 2008, Shuli Liu [9] studied a novel heat recovery/cooling system to carry out low energy cooling with a low emission of $\mathrm{CO}_{2}$. This system is very useful for a hot and wet climate with the abundance of solar energy. The economic analysis based on a case (office of $200 \mathrm{~m} 2$ in London) indicated that the new system of cooling and recovery of heat could save energy $5134 \mathrm{kWh}$ as prevent the emission of $3123 \mathrm{~kg} \mathrm{CO} 2$ annually compared with a traditional system. The capital and maintenance costs of this system of cooling are higher than the traditional system, but its cost of operation are the much lower last. It showed that the new system of cooling and heat recovery is profitable and friendly to environment.

In many places in India, the air-conditioning in the summer is used not only for the comfort of the occupants but to also improve their productivity. Jain [10] presented a cooling system composed by a regenerator and dehumidifier. Theoretical and experimental studies are presented to the principal components of a liquid desiccant cooling system and a comparison of the two results. By changing the air temperatures and the ratio of moisture and the solution flow rates, the operating conditions of dehumidifier and regenerator varied.

Grossman and Gommed noted that the desiccant systems of cooling liquids had good cooling the performance in the hot and wet climates as in the Mediterranean countries solving the problem of the lack to cool air. The system was worked since April 2003 [11] studied and examined a liquid desiccant system for cooling and dehumidification, it includes a novel heat/mass exchanger (HME) designed to reserve a liquid desiccant with the regenerator and the 
dehumidifier and to allow the mass transfer between them with a minimum thermal losses.

In this paper we present a research project, in progress, whose objective is to set up a desiccant cooling system.

It could to minimize fossil fuel-based energy use, reduce electricity demand and to achieve low energy cooling with low $\mathrm{CO}_{2}$ emission. The system incorporates a solar thermal collector, a dehumidifier, a cooling tower, heat exchangers and a building. We present an analytical solution of heat and mass transfer processes in system cores and also results of the simulation computer code. The project aims at assessing the effectiveness of this kind of a desiccant cooling technology under Tunisian climatic conditions.

\section{Climate AND ENERgy CONSIDERATIONS IN TUNIS}

Tunisia has a high level of solar power with an average direct irradiation which varies from $2 \mathrm{kWh} / \mathrm{m}^{2} /$ day in the extreme north to $6 \mathrm{kWh} / \mathrm{m} 2 /$ day in the zones of the extreme south [12]. It receives an average of $4 \mathrm{kcal} / \mathrm{m} 2 /$ day with a total insolation period of $3500 \mathrm{~h} /$ year and 350 sunny days per year [13]. As we can see in Fig. 1 there is an abundant solar energy in overall the country of Tunisia from the north (Tunis) to the south (Tatouin) which must be explored and especially to produce the cooling demand and to provide the occupants with healthy and productive environments [14].

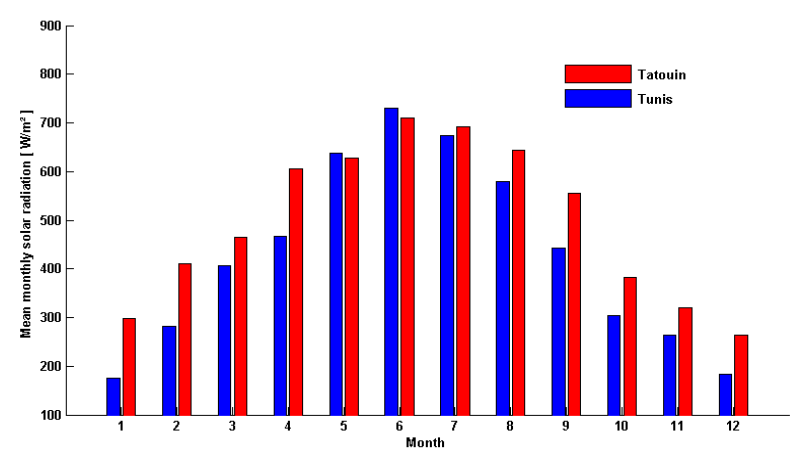

Fig. 1. Mean monthly solar radiation intensities in Tunis and Tatouin.

The indoor comfort conditions, as presented in Table I by setting the desired zone temperature and humidity ratio at $25^{\circ} \mathrm{C}$ and $50 \%$ in summer and $20^{\circ} \mathrm{C}$ and $60 \%$ in winter. We have exploited in this study climatic data collected from a two meteorological stations the first one is placed at the Sahara (southern zone) and the other is at the northern coast.

\begin{tabular}{lcc}
\multicolumn{2}{c}{ TABLE I: THE ARRANGEMENT OF CHANNELS } \\
\hline \hline & Summer & Winter \\
\hline Temperature $\left({ }^{\circ} \mathrm{C}\right)$ & 25 & 20 \\
Relative Humidity $(\%)$ & 50 & 60 \\
\hline \hline
\end{tabular}

\section{DESCRIPTION OF THE SYSTEM}

The liquid desiccant system is designed to serve as an open-cycle absorption system that can operate with low grade solar heat. The system consists of six components: an air dehumidifier, a solution regenerator, two water-to-solution heat exchangers, a solution-to-solution heat exchanger, and air-to-air heat exchanger, a schematic description of a system is given in Fig. 2.

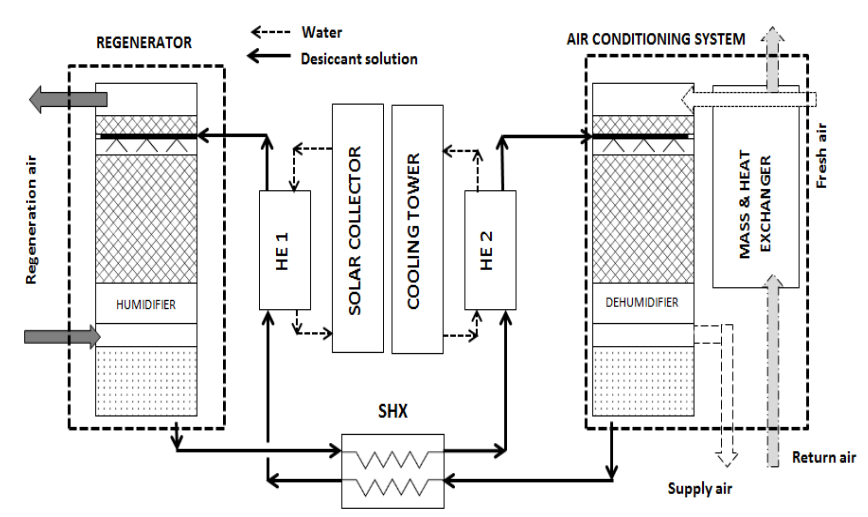

Fig. 2. Description of liquid desiccant system.

When the fresh air enters the system into the dehumidifier, it makes contact with the concentrated and cool liquid desiccant. The fresh air, preliminarily cooled in the heat exchanger recovery (air-to-air heat exchanger), is thus dehumidified and cooled. The liquid desiccant cycle begin by pumped the solution at the bottom of the dehumidifier, passes through the solution to solution heat exchanger to be preheated, then it's heated until regeneration temperature by solar energy, and finally it's sprayed in the regenerator to be concentrated.

\section{ChOISE OF LIQUID DESICCANT SOLUTION}

From the researches in hydroscopic substances, it can be said that a large number of solution used in the cooling system ( $\mathrm{LiCl}, \mathrm{LiBr}, \mathrm{CaCl}_{2}, \mathrm{KCOOH}$,etc), but the choice of the adequate liquid desiccant solution is based on four important parameters which are : vapor pressure, solution concentration and it is the crystallization limit, and the regeneration temperature and finally the price of desiccant solution.

A comparison study between $\mathrm{LiCl}$ and $\mathrm{LiBr}$ solutions frequently used HRDC system proves that the efficient one is the $\mathrm{LiCl}$ solution because it is more used owing to its higher absorption ability and relatively lower regenerator temperature $\left(60-65^{\circ} \mathrm{C}\right)$ and high crystallization limit. Although it is corrosive but not a toxic material and does not pose any health hazards and its cost lower compared with $\mathrm{LiBr}[15]$.

An experimental analysis carried by Pietruschka [16], it deduced that the calcium chloride solution $\mathrm{CaCl}_{2}$ provided lower dehumidification potential that the lithium chloride solution $\mathrm{LiCl}$ which had a cheaper price and no causticity with metal. The lithium chloride solution gave 40-50\% higher dehumidification rates over a wide relative humidity range.

From the different types of liquid desiccants are available in the market, the lithium chloride $\mathrm{LiCl}$ selected as a desiccant solution to use in this study.

\section{MATHEMATICAL FoRMUlation}

Many researchers has developed mathematical models of the coupled heat and mass transfer processes in the ACS or regenerator, and most of the models were solved numerically [17], [18]. In this part, we present a schematic model and an analytical solution of heat and mass transfer processes in the 
principal components of a liquid desiccant cooling system.

Fig. 3 shows a schematic model of the liquid desiccant system and the circle of desiccant solution, where, the different number $(1,2,3,4,5$, and 6$)$ is the solution position in the operating circle.

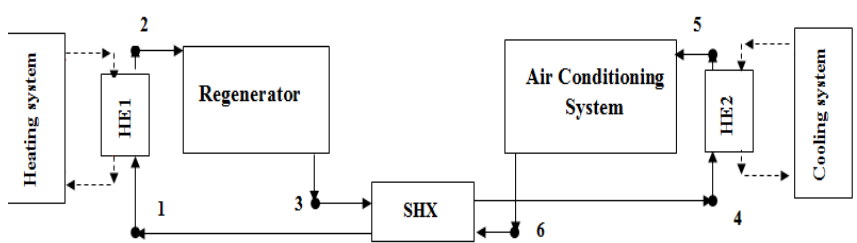

Fig. 3. Diagram of the desiccant cycle.

The following assumptions are made for the analysis:

1) The mathematical formulation was developed under steady state conditions.

2) The specific heat of the fluids with respect to the temperature is constant.

3) The heat loss through the regenerator and dehumidifier was negligible.

4) The desiccant inlet temperature is different from the inlet temperature of air.

\section{A. Regeneration Process}

The balance of heat and mass is written for a long of core regenerator $L$, where we consider that air and solution desiccant in the opposite direction. The desiccant outlet temperature is defined as:

$$
\theta_{\text {sol3 }}=\frac{H_{\text {sol } 2}+m_{\text {air }} *\left[\begin{array}{l}
\left(H_{\text {air }, \text { de , in }}-H_{\text {air }, \text { deh }, \text { out }}\right)+ \\
\lambda_{\text {des }} *\left(W_{\text {air }, \text { deh, out }}-W_{\text {air }, \text { deh }, \text { in }}\right)
\end{array}\right]}{\left(m_{\text {sol3 }} * C_{\text {sol }}\right)}
$$

where $m_{\text {air }}$ is the air mass flow rate $(\mathrm{Kg} / \mathrm{s}), m_{\text {sol }}$ is the desiccant solution mass flow rate $(\mathrm{Kg} / \mathrm{s})$, Hair is the enthalpy of the air stream $(\mathrm{J} / \mathrm{kg}), W_{\text {air }}$ is air humidity ratio $(\mathrm{Kg} / \mathrm{Kg})$ and $C_{\text {sol }}$ is desiccant solution specific heat capacity $(\mathrm{J} / \mathrm{kg} \mathrm{K})$.

The solution desiccant concentration at outlet of the regenerator is given by:

$$
\zeta_{3}=\frac{m_{\text {sol } 2}}{m_{\text {sol } 3}} * \zeta_{2}
$$

where, $\zeta$ is the solution concentration.

\section{B. Dehumidification Process}

In this part, the air stream is dehumidified and cooled by the strong/cold solution in the dehumidifier core, the desired air temperature and moisture content at the outlet of air conditioning system (ACS) is described as the following:

$$
\begin{array}{r}
m_{\text {air }} *\left(C_{s}+C_{v} * W_{\text {air }, \text { deh }, \text { in }}\right)- \\
\theta_{\text {air }, \text { deh,out }}=\frac{\eta_{\text {deh }} *\left(H_{\text {sol } 6}-H_{\text {sol } 5}\right)}{\left(C_{s}+C_{v} * W_{\text {air }, \text { deh, in }}\right)}
\end{array}
$$

where, $H_{\text {sol }}$ is the enthalpy of the desiccant solution $(\mathrm{J} / \mathrm{kg})$.

$$
W_{\text {air,deh,out }}=W_{\text {air,deh,in }}-\eta_{\text {deh }} *\left(W_{\text {air,exh }}-W_{\text {air,deh,in }}\right)
$$

The desiccant solution at the outlet of the ASC in terms of the known solution and air temperatures at the inlet, the solution desiccant outlet temperature is defined as:

$$
\theta_{\text {sol6 }}=\frac{H_{\text {sol5 }}+m_{\text {air }} *\left[\begin{array}{l}
\left(H_{\text {air }, \text { de ,in }}-H_{\text {air }, \text { deh }, \text { out }}\right)+ \\
\lambda_{\text {abs }} *\left(W_{\text {air, deh,out }}-W_{\text {air }, \text { deh }, \text { in }}\right)
\end{array}\right]}{\left(m_{\text {sol6 }} * C_{\text {sol }}\right)}
$$

where, $\lambda_{a b s}$ is the enthalpy of absorption (dilution) $(\mathrm{J} / \mathrm{kg})$, which is defined for the aqueous solution of lithium chloride as [19]:

$$
\begin{aligned}
& \lambda_{a b s}=\left(169.105+457.850 \times\left(273+\theta_{\text {sol }}\right)\right) \times \\
& {\left[1+\left(\frac{\zeta}{0.845 \times(0.6-\zeta)}\right)^{-1.965}\right]^{-2.265}}
\end{aligned}
$$

The desiccant concentration at outlet of the ACS is given by:

$$
\zeta_{6}=\frac{m_{\text {sol5 }}}{m_{\text {sol } 6}} \times \zeta_{5}
$$

\section{Heating and Cooling Systems}

The temperature of cooled water leaving the cooling system (cooling tower) is assumed to be lower than the solution temperature .entering in the heat exchanger (HE2) and the effectiveness of the cooling tower is assumed constant equal to 0.8 . The heat transfer rate $\left(Q_{\text {cool }}\right)$ transferred from the solution to the cold water is calculated:

$$
Q_{\text {cool }}=m_{\text {sol } 4} \times C_{\text {sol }} \times\left(\theta_{\text {sol } 4}-\theta_{\text {sol } 5}\right)
$$

The energy consumption rate of the cooling system $\left(E_{\text {cool }}\right)$ is calculated by the equation as follows:

$$
E_{\text {cool }}=\frac{Q_{\text {cool }}}{0.8}
$$

The temperature of heated water leaving is assumed to be higher than the solution temperature entering in the heat exchanger (HE1) and the effectiveness is assumed constant equal to 0.8 . The heat transfer rate $\left(Q_{\text {heat }}\right)$ transferred from the hot water to the solution is calculated:

$$
Q_{\text {heat }}=m_{\text {sol } 1} * C_{s o l} *\left(\theta_{\text {sol } 2}-\theta_{\text {sol } 1}\right)
$$

The energy consumption rate of the heating system $\left(E_{\text {heat }}\right)$ is calculated by the equation as follows:

$$
E_{\text {heat }}=\frac{Q_{\text {heat }}}{0.8}
$$


Electrical energy (Eel) consumed in this system, we take the electrical consumption of the example of Shuli Liu system (Shuli Liu, 2008), which is like our system, which require a small amount of energy with the maximal value of about 500W (There are 6 pumps (30W) and 3 fans (100W)).

\section{Performance of the Desiccant Cycle Process}

In this part, we present the coefficient of performance $(C O P)$ to describe the working performance of the global system. As the definition of $C O P$,

$$
C O P=\frac{\text { producing_energy }}{\text { input_energy }}
$$

The output energy (cooling capacity) is energy reduction from the fresh air to supply air as shown in the following:

$$
C C=m_{\text {air }} \times C_{s} \times\left(\theta_{\text {freshair }}-\theta_{\text {supplyair }}\right)
$$

The COP is defined as the ratio between the cooling capacity and the total primary energy consumption in the whole liquid desiccant system, it should be considered in two conditions: when natural energy is unavailable, and natural energy is sufficient.

1) When no renewable energy is utilized, the $C O P$ of the whole system is:

$$
C O P 1=\frac{C C}{\left(E_{\text {cool }}+\left(E_{\text {el }} / 0.3\right)\right)+E_{\text {heat }}}
$$

2) When renewable heating and cooling energy are utilized, the $C O P$ of the whole system is:

$$
C O P 2=\frac{C C}{E_{e l} / 0.3}
$$

where, 0.3 is the assumed equivalent conversion coefficient of electric power to thermal energy.

\section{NUMERICAL RESULTS}

\section{A. Air thermal Process and Desiccant Solution Cycle Thermal Process}

In this part, Fig. 4 presents the air thermal process on psychometric chart in a typical summer day (at 13:00). The fresh air is pre-cooled and dehumidified from point 1 to point 2 by heat and mass transfer to the existing air in the heat/mass exchanger. Then into the desiccant dehumidifier core, the fresh air is cooled and dehumidified until point 3 to supply into the building. The exhaust air humidity and temperature is varied from point (i) into psychometric chart to point 4 through the air to air heat/mass exchanger and then exits.

The air Temperature and humidity ratio values of circle thermal process are presented in Table II.

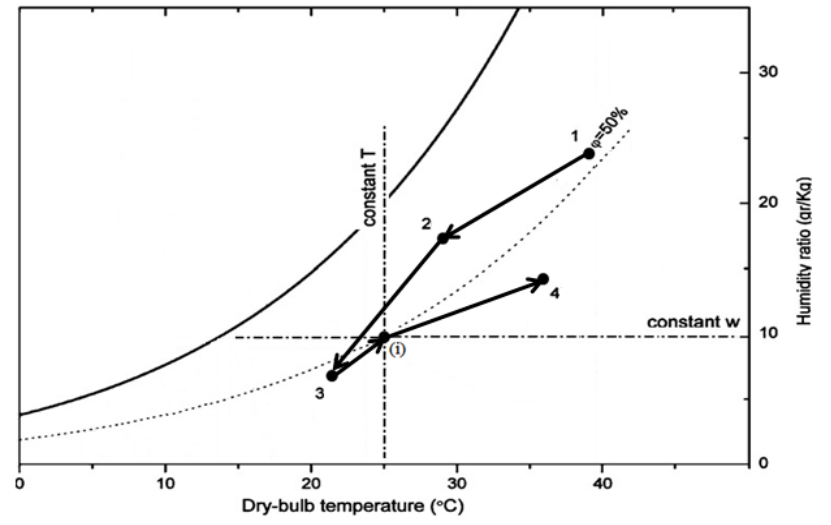

Fig. 4. Air thermal process on psychometric chart.

TABLE II: AIR THERMAL PROCESS

\begin{tabular}{lcc}
\hline \hline & $\mathrm{T}_{\text {air }}\left[{ }^{\circ} \mathrm{C}\right]$ & $\mathrm{W}_{\text {air }}[\mathrm{g} / \mathrm{Kg}]$ \\
\hline Point 1 & 39.22 & 23.9 \\
Point 2 & 28.16 & 18.1 \\
Point 3 & 21.34 & 7.3 \\
Point (i) & 25 & 9.8 \\
Point 4 & 36.38 & 14.8 \\
\hline \hline
\end{tabular}

Fig. 5 shows the desiccant solution cycle process on Chart of equilibrium between the vapor pressure of aqueous solutions of lithium chloride and the partial pressure of water vapor in the air, at the normal sea level atmospheric pressure [18]. Before entering the regenerator, the weak desiccant solution (point 1) is heated by a hot water coming from the heating system (point 2), which the water vapor is removed from the weak desiccant solution to the regeneration air. Then, the strong desiccant solution from the regenerator (point 3) pre-cooled by passing in sensible heat exchanger (SHX), resulting in a lowered temperature state to point 4. However, on the way to the air conditioning system, the desiccant solution temperature decreases due to absorbing heat from the cool water coming from the cooling system to the desiccant solution in the heat exchanger (HE2) (point 4 to 5).In the dehumidifier core, the moisture and part of the heat moves from the passing air by a strong desiccant solution (point 5 to 6).

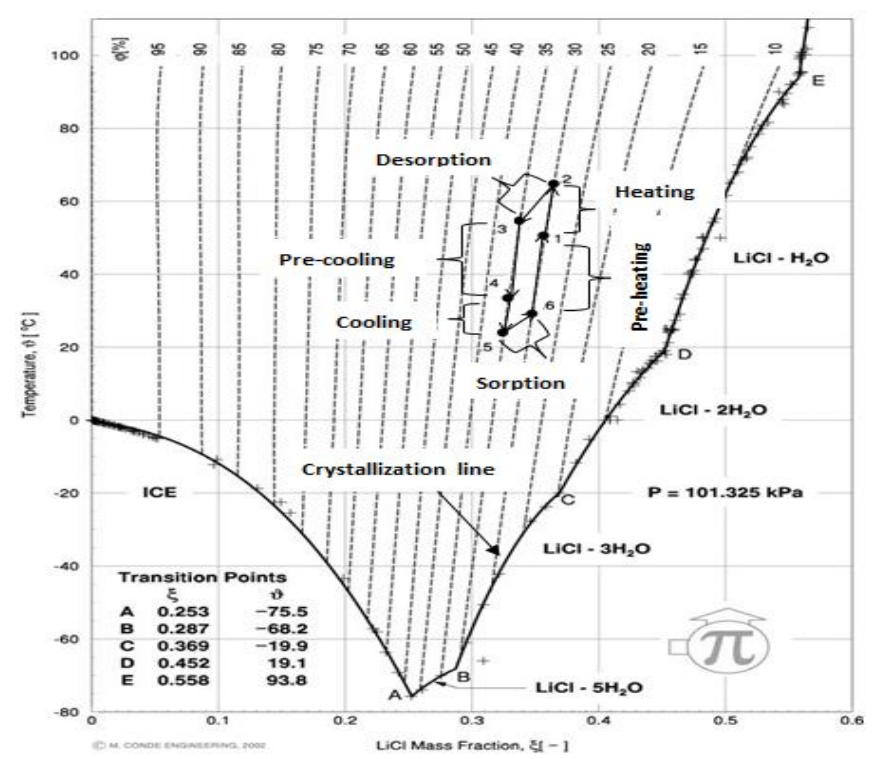

Fig. 5. Desiccant solution cycle thermal process. 
Both desiccant solution temperature and concentration values are presented in Table III.

TABLE III: DESICCANT SOLUTION CYCLE THERMAL PROCESS

\begin{tabular}{lcc}
\hline \hline & $\mathrm{T}_{\text {sol }}\left[{ }^{\circ} \mathrm{C}\right]$ & $\zeta_{\text {sol }}[\%]$ \\
\hline Point 1 & 49.61 & 30 \\
Point 2 & 64.58 & 30 \\
Point 3 & 55.17 & 35 \\
Point 4 & 32.94 & 35 \\
Point 5 & 23.01 & 35 \\
Point 6 & 27.39 & 30 \\
\hline \hline
\end{tabular}

\section{B. Typical Summer Day Results}

Fig. 6 presents the climatic conditions (solar radiation, ambient temperature) for a sunny day representative of the month of August chosen from data file. The results of simulation related to one typical day of summer (02/08). In summer, it is expected that the temperature of the ambient humid air that enters the dehumidifier is higher than the solution inlet temperature. Hence, in addition to moisture transfer, heat transfer will also occur due to the temperature difference. The primary objective of the dehumidification process is to remove water vapor from the ambient humid air [20].

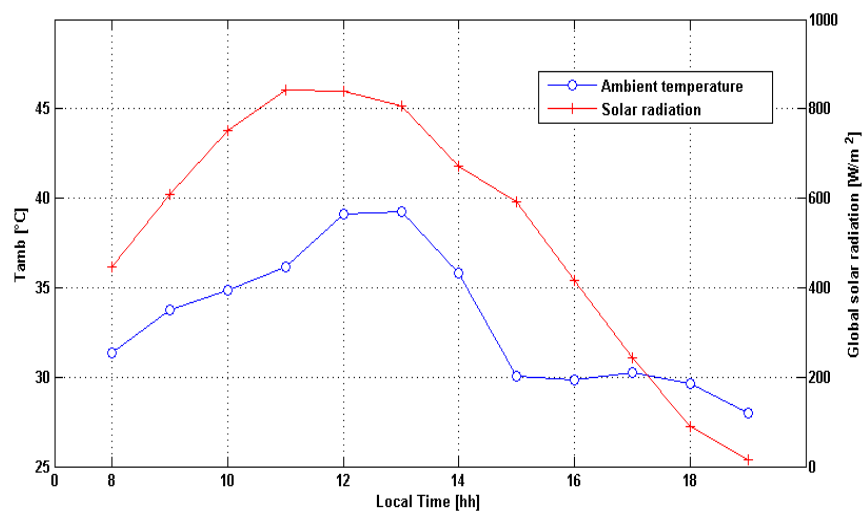

Fig. 6. Climatic conditions (solar radiation, ambient temperature).

Fig. 7 presents the air specific humidity (absolute) at the inlet and outlet of air conditioning system under the indicated climatic conditions. The inlet specific humidity decreased between 40-65\% in this typical day, this deference between inlet and outlet is proportional to moisture transfer during an air dehumidification process.

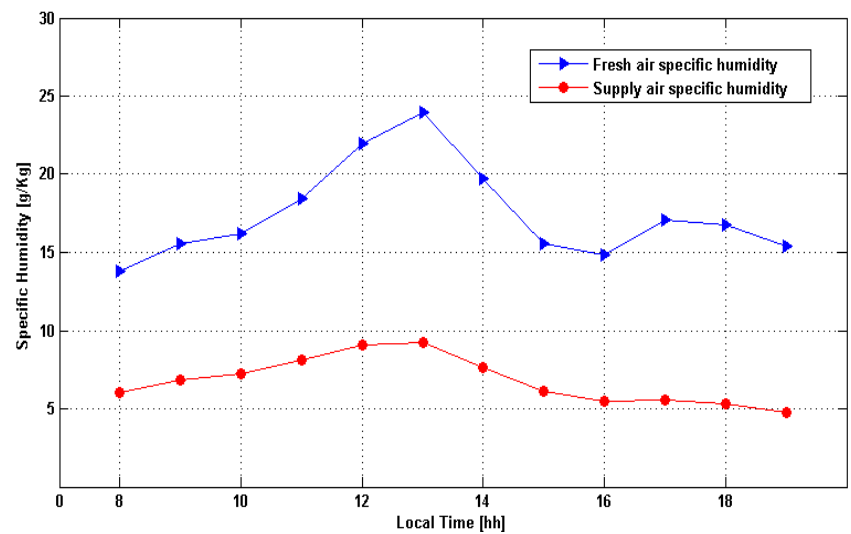

Fig. 7. Air specific humidity at inlet and outlet of air conditioning system.
Fig. 8 presents the air temperatures at the inlet and the outlet of the air conditioning system under the indicated climatic conditions. The supply air temperature is expected to be lower than that of the inlet air due to the contact of the air stream with the cool and strong desiccant solution. This is confirmed with the experimental data given by Chung [21].

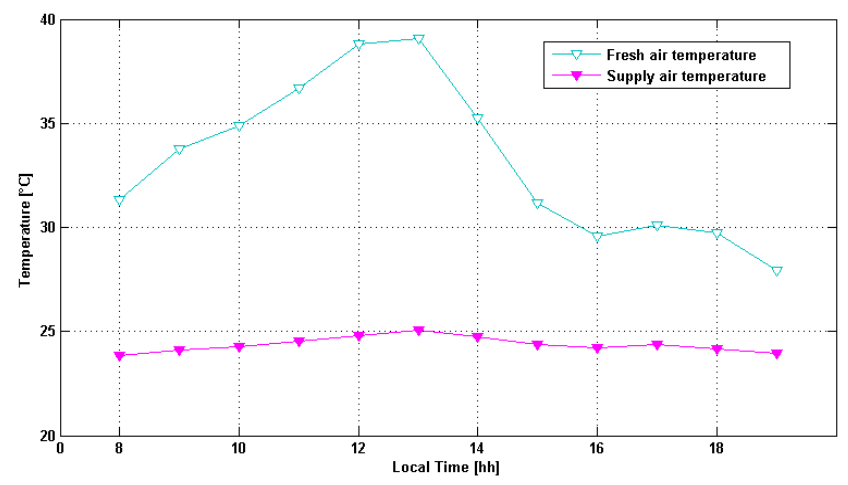

Fig. 8. Air temperature at inlet and outlet of air conditioning system.

Fig. 9 presents the coefficient of performance (COP) of the global system. By varying the climatic conditions, it can be seen that the climatic conditions greatly influenced the COP, the COP1 without renewable energy is as low as 1 , when the renewable heating and cooling energy are both available, the COP2 of the system is 3.0. This is proving that the use of renewable energy sources is an efficient to improve the COP of the desiccant cooling system and minimize the electrical energetic consumption.

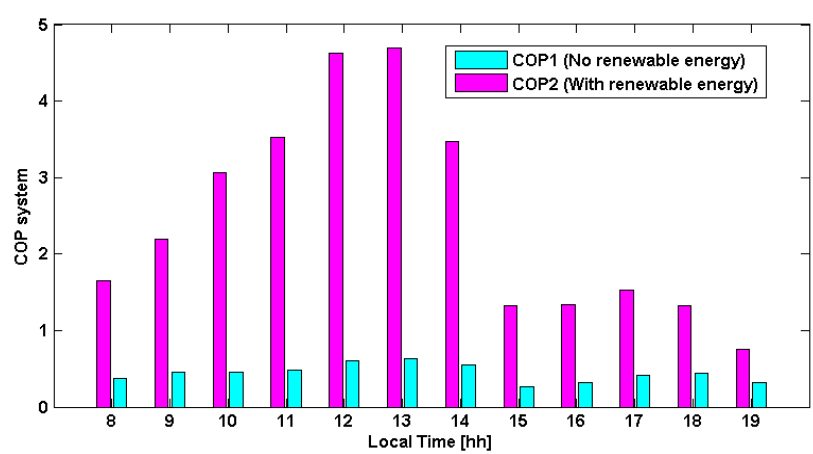

Fig. 9. Coefficient of performance of the heat recovery/cooling desiccant.

\section{CONCLUSION}

The objective of this study is to present a research project which aims at assessing the effectiveness of this of a desiccant cooling technology under Tunisian climatic conditions. A simulation computer code is carried to test this kind of system. The simulation results show that the heat recovery/desiccant cooling system is effective and can be functional for Tunisian climatic conditions. There is efficient in the hot and humid places and in Tunisia. We can use this system only on the Mediterranean places, however the other places were very dry and hot, for example Tatouin was in the south of Tunisia, we can't use this system for many problem first the climatic conditions of this place in the summer and another problem it is the low water sources for heating and cooling the desiccant solution. This system of cooling is profitable and offers an alternative solution to minimize energy related emissions of $\mathrm{CO}_{2}$ and reduce electricity 
demand. To validate these results we will test this system by an experimental work under the real weather conditions.

\section{REFERENCES}

[1] L. Perez-Lombard, J. Ortiz, and C. Pout, "A review on buildings energy consumption in formation," Energy Build, vol. 40, pp. 394-398, 2008.

[2] A. Kakabaev, N. Kurbanov, O. Klyshchaeva, and G. Redzhepov, "Storage of cold in an open-cycle solar absorption cooling system," Geliotekhika, vol. 17, pp. 64-66, 1981.

[3] G. Grossman and A. Johannsen, "Solar cooling and air conditioning," Progress in Energy and Combustion Science, vol. 7, pp. 185-228, 1981.

[4] V. Oberg and D. Y. Goswami, "A review of liquid desiccant cooling," Advances in Solar Energy, vol. 12, ch. 10, pp. 431-470, 1998.

[5] G. Grossman, "Solar-powered systems for cooling, dehumidification and air-conditioning," Solar Energy, vol. 72, pp. 53-62, 2002.

[6] P. Mavroudaki, C. B. Beggs, P. A. Sleigh, and S. P. Halliday, "The potential for solar powered single stage desiccant cooling in Southern Europe," Applied Thermal Engineering, vol. 22, pp. 1129-1140, 2002.

[7] W. Y. Saman and S. Alizadeh, "An experimental study of a cross-flow type plate heat exchanger for dehumidification/ cooling," Solar Energy, vol. 73, pp. 59-71, 2002

[8] K. Gommed and G. Grossman, "Experimental investigation of a liquid desiccant system for solar cooling and dehumidification," Solar Energy, vol. 81, pp. 131-138, 2007.

[9] S. L. Liu, "A novel heat recovery/desiccant cooling system," Ph.D. dissertation, University of Nottingham, May 2008.

[10] S. Jain, P. L. Dhar, and S. C. Kaushik, "Experimental studies on the dehumidifier and regenerator of a liquid desiccant cooling system," Applied Thermal Engineering, vol. 20, pp. 253-267, 2002.

[11] K. Gommed and G. Grossman, "Investigation of an improved solar-powered open absorption system for cooling, dehumidification and air conditioning," International Journal of Refrigeration, vol. 35, pp. 676-684, 2012.

[12] United Nations (UN), Office for Africa of North, The Renewable Energy Sector for North Africa Situation Current and Perspective Economic Commission on Africa, September 2012, p. 32.

[13] F. Benjemaa, I. Houcine, and M. H. Chahbani, "Potential of renewable energy development for water desalination in Tunisia," Renewable Energy, vol. 18, no. 3, pp. 331-347, 1999.

[14] National Agency for Energy Conservation Tunisia (NAEC). [Online]. Available: http://www.anme.nat.tn.

[15] K. Gommed and G. Grossman, "A liquid desiccant system for solar cooling and dehumidification," Solar Energy Engineering ASME, vol. 126, p. 879, 2004.

[16] D. Pietruschka, U. Eicker, M. Huber, and J. Schumacer, "Experimental performance analysis and modeling of liquid desiccant cooling systems for air conditioning in residential buildings," International Journal of Refrigeration, vol. 29, pp. 110-124, 2006.

[17] D. Babakhani and M. Soleymani, "Simplified analysis of heat and mass transfer model in liqid desiccant regeneration process," Journal of the Taiwan Institute of Chemical Engineers, vol. 41, pp. 259-267, 2010.

[18] M. R. Conde, "Properties of aqueous solutions of lithium and calcium chlorides: Formulations for use in air conditioning equipment design," International Journal of Thermal Sciences, vol. 43, pp. 367-382, 2004.

[19] E. F. Johnson and M. C. Molstad, "Thermodynamic properties of aqueous lithium chloride solutions-An evaluation of the gas curren method for the determination of the thermodynamic properties of aqueous salt solutions," J. Phys. Colloid Chem., vol. 55, pp. 257-281, 1951.

[20] P. Gandhidasan, "A simplified model for air dehumidification with liquid desiccant," Solar Energy, vol. 76, pp. 409-416, 2004.

[21] T. W. Chung, T. K. Ghosh, and A. L. Hines, "Dehumidification of air by aqueous lithium chloride in a packed column," Separation Science and Technology, vol. 28, pp. 533-550, 1993.

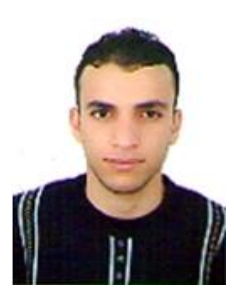

S. Sabek was born in Tunisia, 1987. He got his master degree in energetic and transfers at the University of Tunisia in 2012; and he prepares a Ph. D in physic at the University of Tunisia in 2013.

His research activities are focused on renewable energies technologies and heat and mass transfer simulation.

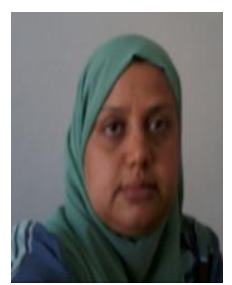

K. Ben Nasr was born in Tunis in 1975 , she is an assistant professor in the National School of Architecture and Urbanism in Carthago, Tunisia. She is a $\mathrm{PhD}$ holder in mechanical engineering from the University of Tunis since 2008. Her research activities are focused on renewable energies and heat transfer simulation and thermal building. She published serveral papers in international journals related to these subjetcts.

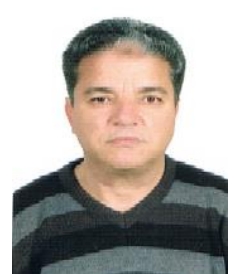

R. Chouikh was born in Tunis in 1961, he is a lecturer in Higher Institute of Applied Mathematics and Computer Science in Kairouan, Tunisia. He recevied $\mathrm{PhD}$ degree in mechanical engineering from the University of Tunis, in 1998. His research activities are focused on transport phenomena in membrane, porous media and developpement of CFD. He published serveral papers in international journals related to these subjetcts and is involved in national and international projects concerning fuel cell technology and porous media. Dr. Chouikh is a member of Tunisian Society of Physics.

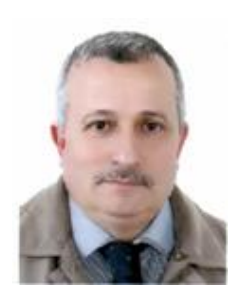

A. Guizani was born in Tunis in 1958, he is a professor in mechanical engineering in the University of Tunis. He recevied $\mathrm{PhD}$ degree in mechanical engineering from the University of Tunis, in 1988. He is the head of the Laboratory Thermal Processes in the Research and Technology Center in Tunis. His research activities are focused on renewable energies and heat transfer simulation. He published serveral papers in international journals related to these subjetcts and is involved in national and international projects concerning fuel cell technology, desalination and renewable energy. Prof. Guizani is a member of Tunisian Society of Physics. 